\title{
Fluoride removal performance of phosphoric acid treated lime: Breakthrough analysis and point-of-use system performance
}

\author{
Cyprian Murutu', Maurice S Onyango ${ }^{1 *}$, Aoyi Ochieng ${ }^{2}$ and Fred AO Otieno ${ }^{3}$ \\ ${ }^{1}$ Department of Chemical and Metallurgical Engineering, Tshwane University of Technology, Private Bag X680, Pretoria, South Africa \\ ${ }^{2}$ Department of Chemical Engineering, Vaal University of Technology, South Africa \\ ${ }^{3}$ Durban University of Technology, Durban, South Africa
}

\begin{abstract}
Fluoride in drinking water above permissible levels is responsible for dental and skeletal fluorosis. In this study, removal of fluoride ions from water using phosphoric acid treated lime was investigated in continuous and point-of-use system operations. In the continuous column operations, fluoride removal performance was investigated as a function of the fluoride concentration, flow rate and amount of adsorbent mass. Early saturation and lower fluoride removal were observed at higher flow rate and initial concentration, and at lower mass. Two domestic defluoridation point-of-use systems operated intermittently to process $20 \ell \cdot$ day $^{-1}$ of water were used. High fluoride uptake capacity (FUC) from groundwater was observed depicting the suitability of the new media in defluoridation. However, further research is required to optimise the point-ofuse systems performances.
\end{abstract}

Keywords: adsorption, lime, fluoride, breakthrough

\section{Nomenclature}

BV Bed volumes

$C_{\mathrm{o}} \quad$ Initial concentration of solute $\left(\mathrm{mg} \cdot \ell^{-1}\right)$

$C_{b} \quad$ Desired concentration of solute at breakthrough $\left(\mathrm{mg} \cdot \ell^{-1}\right)$

DDU Domestic defluoridation unit

FUC Fluoride uptake capacity $\left(\mathrm{mg} \cdot \mathrm{kg}^{-1}\right)$

$K \quad$ Adsorption rate constant $\left(\ell \cdot \mathrm{mg}^{-1} \cdot \mathrm{h}^{-1}\right)$

$N_{\text {o }} \quad$ Adsorption capacity $\left(\mathrm{mg} \cdot \ell^{-1}\right)$

POU Point of use

$t \quad$ Service time of column under above conditions (h)

$V \quad$ Linear flow velocity of feed to bed $\left(\mathrm{cm} \cdot \mathrm{h}^{-1}\right)$

$x \quad$ Bed depth of column $(\mathrm{cm})$

$x_{0} \quad$ Critical bed depth $(\mathrm{cm})$

\section{Introduction}

Fluoride in drinking water can be either beneficial or detrimental to health, depending on its concentration. The presence of fluoride in drinking water within permissible limits is beneficial in the calcification of dental enamel. According to the World Health Organization (WHO), the maximum acceptable concentration of fluoride is $1.5 \mathrm{mg} \cdot \ell^{-1}$ (WHO, 2006), while South Africa's acceptable limit is $0.75 \mathrm{mg} \cdot \ell^{-1}$ (Regulations on Fluoridating Water Supplies, 2000). Concentrations above this level lead to dental and skeletal fluorosis and lesions of the endocrine glands, thyroid and liver (Meenakshi et al., 2004; Misra and Mishra, 2007). It is therefore necessary to remove the excess amount of fluoride from drinking water if the concentration is higher than the permissible limit.

The popular technologies for the removal of fluoride from water include: coagulation followed by precipitation, membrane

\footnotetext{
* To whom all correspondence should be addressed.

용 +27 12 3823533; fax: +27 123823533 ;

e-mail: OnyangoMS@tut.ac.za

Received 25 November 2010; accepted in revised form 2 April 2012.
}

processes, ion exchange and adsorption (Bhatnagr et al., 2011; Huo et al., 2011; Meenakshi and Maheshwari, 2006; Ndiaye et al., 2005; Mohapatra et al., 2009). In coagulation, trace amounts of fluoride ions tend to remain in solution due to solubility restriction. Other shortcomings include the resulting high $\mathrm{pH}$ of the treated water and the generation of large amount of wet bulky sludge (Gong et al., 2012; Pinon-Miramontes et al., 2003). The Nalgonda technique, based on precipitation processes, is also a common defluoridation technique. The limitations of the process are: daily addition of chemicals, large amount of sludge production, and low effectiveness for water having high total dissolved solids and hardness. Further, increases in residual aluminium in the treated water have been reported (Gupta, 1997). This may endanger human health as concentrations of aluminium, a neurotoxin, as low as $8.0 \times 10^{-2} \mathrm{mg} \cdot \ell^{-1}$ in drinking water have been associated with Alzheimer's disease (Simate et al., 2012; Yadav et al., 2006). Membrane processes, though effective in fluoride removal, demineralise water completely, besides the high initial and maintenance costs. Ion exchange methods are efficient for fluoride removal, but a tedious and difficult process of preparation of resins as well as the high cost necessitates a search for an alternative technique. Adsorption techniques have been quite popular in recent years due to their simplicity, as well as the availability of wide range of adsorbents. Research has focused on various types of inexpensive and effective adsorption media, such as different clays (Luther et al.,1996; Taleb et al., 2010; Zevenbergen et al., 1996), solid industrial wastes like red mud, spent bleaching earths, spent catalysts and fly ash (Chaturvedi et al., 1990; Cengeloglu et al., 2002; Lai and Liu, 1996; Piekos and Paslawaska, 1999 and Xu et al., 2011), activated alumina, carbonaceous materials (Abe et al., 2004; Li et al., 2003a,b; Ramos et al., 1999), bone charcoal (Mjengera and Mkongo, 2002), natural and synthetic zeolites and other low-cost adsorbents, with various degrees of success (Onyango et al., 2006). This study was motivated by the need to explore locally-available and inexpensive defluoridation media for safe and easy use at both household and small community levels. 
Limestone, a natural material, is abundant in South Africa and several other countries around the world. It has been applied in water treatment to ensure a stable alkalinity and $\mathrm{pH}$ (Kettunen and Keskitalo, 2000). A few researchers have shown its potential in (waste) water defluoridation. More recently, lime, a combustion product of limestone, has been used in fluoride removal (Reardon and Wang, 2000; Fan, Parker and Smith, 2003; Islam and Patel, 2007; Turner, Binning and Stipp, 2005). The results of those studies indicate that limestone and lime may either not reduce the fluoride level to low concentrations applicable to drinking water or not have reasonable fluoride adsorption capacity. For such media to be of value, therefore, their performance must be enhanced by tailoring their physicochemical properties. Hence, the present study explores the drinking water defluoridation potential of phosphoric acid treated lime. The fluoride adsorption performance of the media in continuous operation, against process variables such as initial concentration, flow rate and adsorbent dose, was studied. Besides these, the performance of 2 domestic defluoridation point-of-use systems was investigated, with varying amounts of adsorbent, to ascertain the ability of the media in water defluoridation. The bed depth service time is used to model breakthrough data while the bed volume and fluoride uptake capacity are used as performance indicators for the point-of-use systems.

\section{Materials and methods}

\section{Reagents and stock solutions}

All of the reagents used in this study were of analytical grade. Fluoride stock solution (1 $\left.000 \mathrm{mg} \cdot \ell^{-1}\right)$ was prepared, by dissolving $2.21 \mathrm{~g}$ of NaF in de-ionised water and filling to $1 \ell$. This was then diluted with deionised water to get the required subsequent concentrations.

\section{Sorbent preparation}

Lime was obtained by calcining limestone. The limestone used was obtained from Continental Cement (Pty.) Ltd, South Africa. The calcination process was done at a temperature of $800^{\circ} \mathrm{C}$ for $24 \mathrm{~h}$ using a furnace (Linn High Therm HK 30). Table 1 shows the chemical composition of the calcined phase of the limestone. The calcined material was air-cooled to room temperature and reacted with $50 \%$ orthophosphoric acid. The acid was added drop-wise while the mixture was under constant agitation, and with temperature kept constant at about $50^{\circ} \mathrm{C}$. The resultant precipitate was left in the mother solution overnight and supernatant was then decanted. The precipitate was washed with distilled water and then air-dried overnight. The material prepared in this manner is hereafter referred to as phosphoric acid treated limestone.

\begin{tabular}{|l|c|}
\hline \multicolumn{2}{|c|}{$\begin{array}{c}\text { Table 1 } \\
\text { Chemical composition of calcined } \\
\text { limestone }\end{array}$} \\
\hline Component & Composition, \% \\
\hline $\mathrm{SiO}_{2}$ & 5.95 \\
\hline $\mathrm{Al}_{2} \mathrm{O}_{3}$ & 1.53 \\
\hline $\mathrm{Fe}_{2} \mathrm{O}_{3}$ & 2.83 \\
\hline $\mathrm{CaO}$ & 88.39 \\
\hline $\mathrm{MgO}$ & 1.26 \\
\hline Combustible matter & 38.3 \\
\hline
\end{tabular}

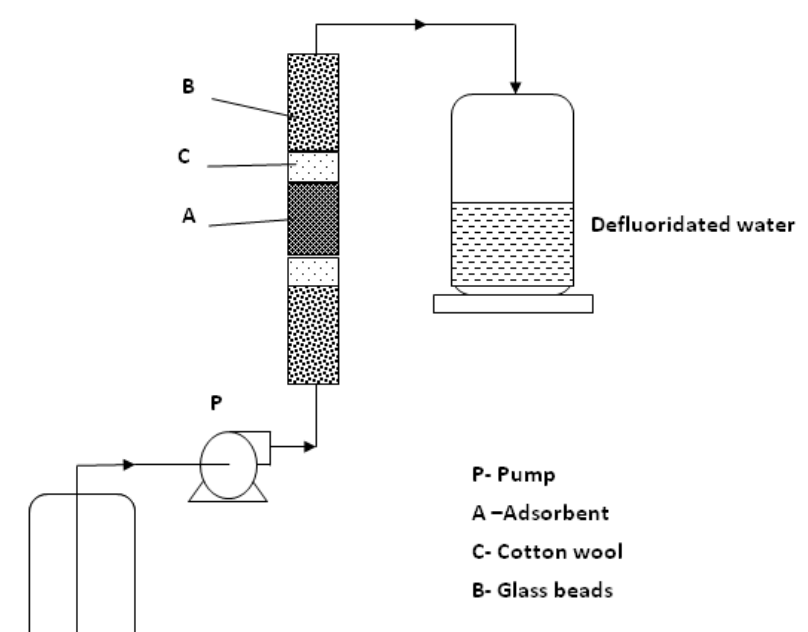

Figure 1

Column experiment set-up

\section{Column studies}

Small-scale column tests were carried out to evaluate the capacity of the media for removing fluoride from water under continuous flow conditions. A Perspex glass cylindrical tube of diameter $30 \mathrm{~cm}$ and height $2.5 \mathrm{~cm}$ was used to conduct the adsorption tests. The column was packed with the desired amount of the media to obtain the desired bed height. A schematic diagram of the column is shown in Fig. 1.

Influent water was pumped through the column with a peristaltic pump (Dynamax Model RP-1). Upward flow of fluid was chosen to minimise channelling inside the column. Samples of the outlet bulk solution were collected at definite intervals of time and examined for fluoride concentration. An ion-selective electrode was used to measure fluoride concentrations in raw and processed waters. The concentration-time data was used to construct breakthrough curves.

\section{Point-of-use systems}

Two point-of-use system designs were used in this study as shown diagrammatically in Figs. 2 and 3. Adsorbent loads were 1.5 and $2 \mathrm{~kg}$ for Model I and II, respectively, with subsequent depths of 27 to $17 \mathrm{~cm}$ (Table 2). Model I is a typical under-thesink filter. Water is pumped via the outer concentric cylinder before flowing upwards though the inner cylinder containing the adsorbent. In the absence of a water supply, a gravity water filter (Model II) enables one to have clean filtered drinking water. Water is poured manually into the upper chamber. It passes through the filter candles under gravity into the lower chamber where the defluoridated water can be accessed via a tap on the side of the filter. Plastic plates with $1.0 \mathrm{~mm}$ diameter holes were used to control raw water flow rate. On the bottom plate, an additional perforated dome is added to reduce both flow rate and channelling.

\begin{tabular}{|l|c|c|}
\hline \multicolumn{3}{|c|}{ Table 2 } \\
Specifications of the point-of-use units \\
\hline Point-of-use unit & Model I & Model II \\
\hline Diameter (cm) (top/bottom) & $10 / 10$ & $25 / 17.5$ \\
\hline Maximum bed height & 30 & 17 \\
\hline Sorbent bed height $(\mathrm{cm})$ & 27 & 17 \\
\hline
\end{tabular}




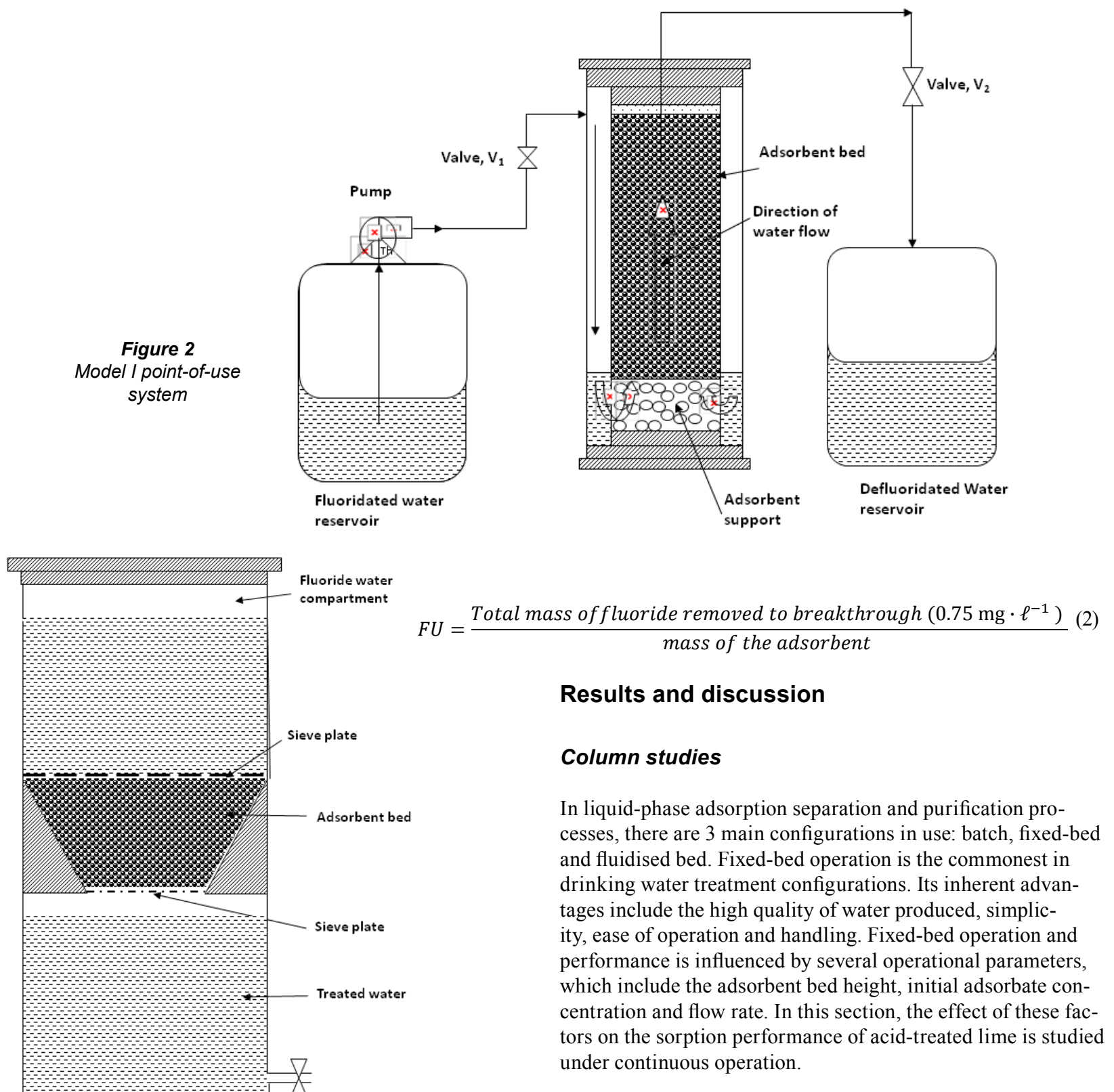

Model II point-of-use system

These units were operated intermittently so as to simulate field conditions. Around $20 \ell$ of raw water were passed through the units per day - a value typical of daily drinking water consumption for a small family. Treated water samples were periodically collected for fluoride analysis.

In this study, the fluoride uptake capacity (FUC) and numbers of bed volume (BV) were used to compare and evaluate the adsorption performance of the bed under the 2 point-of-use system designs and 2 field water samples collected from Venda and Lesodi locations in the Limpopo Province of South Africa. The number of bed volumes (BV) is given by:

$$
B V=\frac{\text { volume of the solution treated }}{\text { volume of adsorbent bed }}
$$

On the other hand, the fluoride uptake capacity was computed by:

\section{Effect of flow rate on breakthrough}

To find out the effect of flow rate on breakthrough curve, adsorption experiments were carried out by varying the flow rate between 2.5 and $8 \mathrm{~m} \ell \cdot \mathrm{min}^{-1}$ using fluoride-spiked water. In this process, the initial fluoride concentration and bed mass were maintained at $10 \mathrm{mg} \cdot \ell^{-1}$ and $20 \mathrm{~g}$, respectively. The effect of flow rate on breakthrough performance at the above operating conditions is shown in Fig. 4. The breakthrough curve becomes steeper when the flow rate is increased and vice versa.

The maximum fluoride uptake capacity for flow rate of 2.5 , 5.0 and $8.0 \mathrm{~m} \ell \cdot \mathrm{min}^{-1}$ were found to be $33.86,27.84$ and 20.93 $\mathrm{mg}$, respectively. With regard to South Africa's maximum permissible fluoride value of $0.75 \mathrm{mg} \cdot \ell^{-1}$, the breakthrough time for the 3 flow rates, in ascending order, were 10.6, 4 and $2 \mathrm{~h}$ respectively. Their respective treated volumes and bed volumes are as shown in Table 3. It is clear from the table that as the flow rate is increased, the treated volume to breakthrough decreases and vice versa. This can be explained by the fact that at lower flow rate, the residence time of the adsorbate is more and hence the adsorbent gets more time to bond with the adsorbate efficiently. In other words, if the residence time of the 


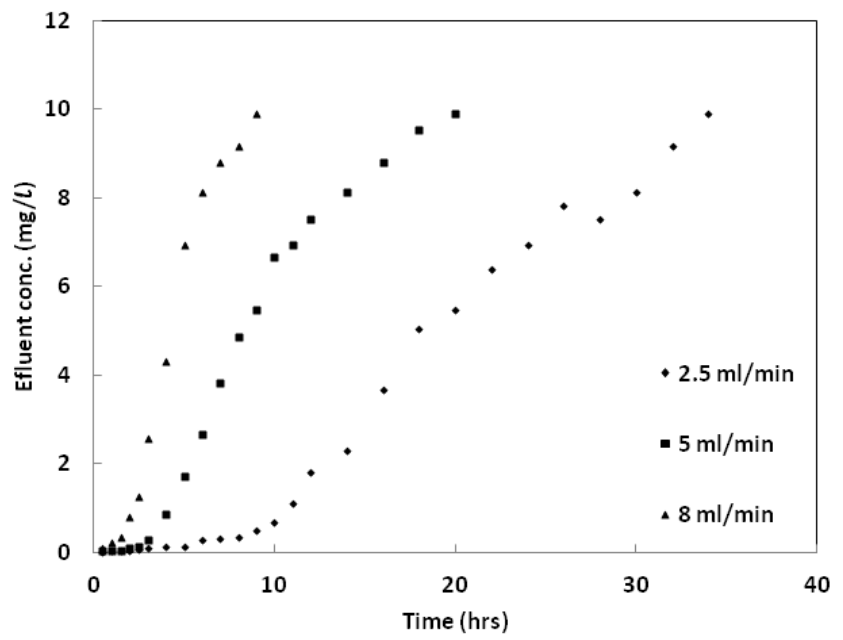

Figure 4

Breakthrough curves for fluoride sorption onto acid-treated lime at different masses. Initial fluoride concentration $=10 \mathrm{mg} / \mathrm{l}$, adsorbent mass $=20 \mathrm{~g}$, temperature $=25^{\circ} \mathrm{C}$.

solute in the column is not large enough for adsorption equilibrium to be reached at the given flow rate, the fluoride solution leaves the column before equilibrium occurs.

\begin{tabular}{|c|c|c|c|}
\hline \multicolumn{4}{|c|}{ Table 3 } \\
Effect of flow rate on column performance \\
\hline $\begin{array}{c}\text { Flow rate } \\
\left(\mathbf{m} \boldsymbol{\cdot} \cdot \mathbf{m i n}^{-1}\right)\end{array}$ & $\begin{array}{c}\text { Breakthrough } \\
\text { time } \mathbf{( h )}\end{array}$ & $\begin{array}{c}\text { Volume treated } \\
(\mathbf{m} \boldsymbol{)})\end{array}$ & $\mathbf{B V}$ \\
\hline 2.5 & 10.6 & 1590 & 65 \\
\hline 5.0 & 4.0 & 1200 & 49 \\
\hline 8.0 & 2.0 & 960 & 39 \\
\hline
\end{tabular}

\section{Effect of initial fluoride concentration on breakthrough}

Fluoride-spiked water with initial concentrations of 5, 10 and $15 \mathrm{mg} \cdot \ell^{-1}$ was passed through the column at a flow rate of $5 \mathrm{~m} \ell \cdot \mathrm{min}^{-1}$. Figure 5 shows the breakthrough results. It is clear that the slopes of the breakthrough curves increase with an increase in initial concentration. Consequently, the breakthrough time decreased with increasing influent fluoride concentration (Table 4). In particular, the times to reach breakthrough point (outflow with fluoride concentration of $0.75 \mathrm{mg} \cdot \ell^{-1}$ ) were 2,4 and $8.5 \mathrm{~h}$ for the 15,10 and $5 \mathrm{mg} \cdot \ell^{-1}$ initial concentrations, respectively. The volumes treated at each of the concentrations are as shown in Table 4 . The volume processed before the breakthrough point is reached, and hence the $\mathrm{BV}$, increases with a decrease in initial concentration.

\begin{tabular}{|c|c|c|c|}
\hline \multicolumn{4}{|c|}{ Table 4 } \\
Effect of initial concentration on breakthrough \\
\hline $\begin{array}{c}\text { Initial conc.( } \\
\left.\text { mg } \cdot \ell^{-1}\right)\end{array}$ & $\begin{array}{c}\text { Breakthrough } \\
\text { time }(\mathbf{h})\end{array}$ & $\begin{array}{c}\text { Volume treated } \\
(\mathbf{m} \boldsymbol{\ell})\end{array}$ & $\mathbf{B V}$ \\
\hline 5 & 8.5 & 2500 & 102 \\
\hline 10 & 4.0 & 1200 & 49 \\
\hline 15 & 2.0 & 600 & 24 \\
\hline
\end{tabular}

During the adsorption process, the initial concentration of a solute affects the rate of consumption of the active sites. As the concentration increases, the driving force for adsorption increases and the active sites are consumed faster. This leads to treatment of smaller volume of water per unit mass of the adsorbent.

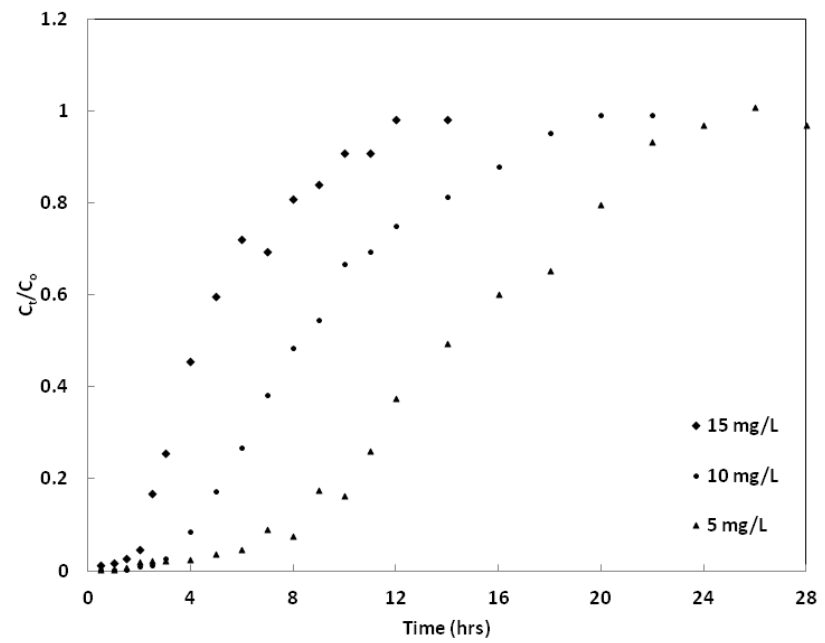

Figure 5

Breakthrough curves for fluoride sorption onto acid-treated lime at different initial fluoride concentrations. Flow rate $=5 \mathrm{ml} / \mathrm{min}$, adsorbent mass $=20 \mathrm{~g}$, temperature $=25^{\circ} \mathrm{C}$.

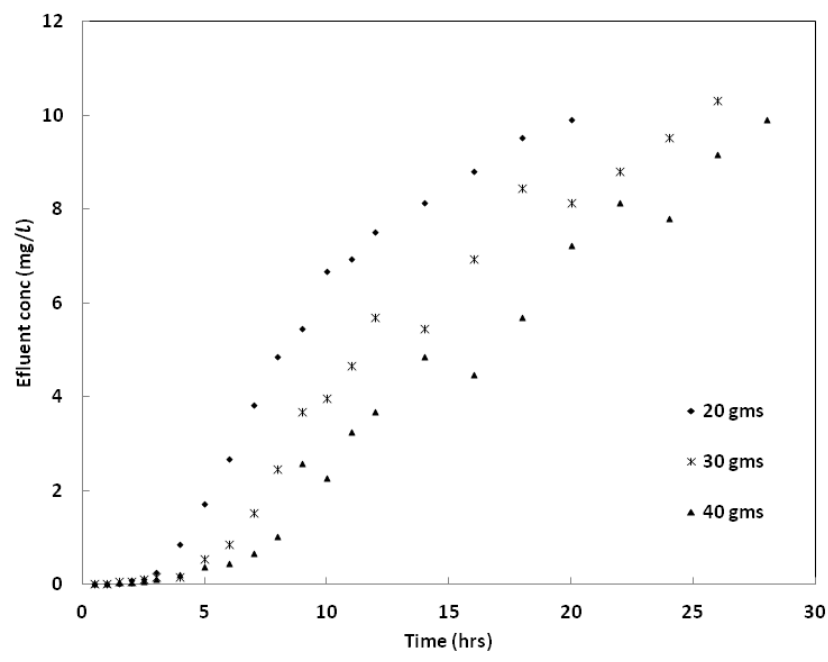

Figure 6

Breakthrough curves for fluoride sorption onto acid-treated lime at different adsorbent masses. Flow rate $=5 \mathrm{m \ell} / \mathrm{min}$, initial fluoride concentration $=10 \mathrm{mg} / \ell$, temperature $=25^{\circ} \mathrm{C}$.

\section{Effect of adsorbent mass/bed height on breakthrough}

In order to find out the effect of bed height on the breakthrough curve, fluoride solution with an initial concentration of 10 $\mathrm{mg} \cdot \ell^{-1}$ and flow rate of $5 \mathrm{~m} \ell \cdot \mathrm{min}^{-1}$ was passed through the adsorption columns of varying adsorbent masses. Figure 6 shows the breakthrough curves at adsorbent masses of 20, 30 and $40 \mathrm{~g}$. The slope of the breakthrough curve decreased with increasing bed height, which resulted in a broadened mass transfer zone. High uptake was observed at the highest bed height. This was due to an increase in the surface area of adsorbent, which provided more binding sites for adsorption. The volumes of water treated at breakthrough point (corresponding to $C_{b}=0.75 \mathrm{mg} \cdot \ell^{-1}$ ) were found to be 1170,1740 and $2220 \mathrm{~m} \ell$, for the 20,30 and $40 \mathrm{~g}$ beds, respectively. The corresponding bed volumes were 48,47 and 46 . From Table 5 , it is evident that the increase in adsorbent mass did not significantly affect the number of bed volumes compared to flow rate and initial 


\begin{tabular}{|c|c|c|c|}
\hline \multicolumn{4}{|c|}{ Table 5 } \\
Effect of adsorbent dose on breakthrough \\
\hline $\begin{array}{c}\text { Adsorbent } \\
\text { mass (g) }\end{array}$ & $\begin{array}{c}\text { Breakthrough } \\
\text { time (h) }\end{array}$ & $\begin{array}{c}\text { Volume treated } \\
\text { (me) }\end{array}$ & BV \\
\hline 20 & 3.9 & 1170 & 48 \\
\hline 30 & 5.8 & 1740 & 47 \\
\hline 40 & 7.4 & 2220 & 46 \\
\hline
\end{tabular}

fluoride concentration. This means that when designing a real system for practical application, lesser emphasis should be laid on the sorbent height than the flow rate and fluoride concentration of the water to be treated.

\section{Application of bed depth service time model (BDST)}

The BDST model is used to predict the column performance for any bed length. Hutchins (1973) proposed a linear relationship between bed depth and service time as follows,

$$
t=\frac{N_{o}}{C_{o} V} x-\frac{1}{C_{o} K} \ln \left(\frac{C_{o}}{C_{b}}-1\right)
$$

where:

$C_{\mathrm{o}}$ is the initial concentration of solute $\left(\mathrm{mg} \cdot \ell^{-1}\right)$

$C_{b}$ the desired concentration of solute at breakthrough $\left(\mathrm{mg} \cdot \ell^{-1}\right)$, i.e, $0.75 \mathrm{mg} \cdot \ell^{-1}$ as per South Africa's standard

$K$ the adsorption rate constant $\left(\ell \cdot \mathrm{mg}^{-1} \cdot \mathrm{h}^{-1}\right)$

$N_{\mathrm{o}}$ the adsorption capacity $\left(\mathrm{mg} \cdot \ell^{-1}\right)$

$x$ the bed depth of column $(\mathrm{cm})$

$v$ the linear flow velocity of feed to bed $\left(\mathrm{cm} \cdot \mathrm{h}^{-1}\right)$

$t$ the service time of column under above conditions (h)

The critical bed depth $\left(x_{0}\right)$ is obtained for $t=0$ and for a fixed outlet concentration $C_{t}=C_{b}$, is given by:

$$
x_{o}=\frac{V}{K N_{o}} \ln \left(\frac{C_{o}}{C_{b}}-1\right)
$$

where:

$C_{b}$ is the concentration at the breakthrough. $C_{b}$ represents the theoretical depth of adsorbent necessary to prevent the sorbate concentration from exceeding the limit concentration $C_{b}$.

A plot of service time against bed depth, following the above model, gives a straight line (Fig. 7) $\left[\right.$ slope $=N_{o} / C_{0} V$, intercept $=$ $\left.\left(1 / K C_{o} \ln \left\{\left(C_{o} / C_{b}\right)-1\right\}\right)\right]$.

The service time and bed depth are correlated with the process parameters such as initial concentration flow rate and adsorption capacity. The slope of the BDST line represents the time required for the adsorption zone to travel a unit length through the adsorbent under the selected experimental conditions at a given concentration; in the present study this was found to be $0.7 \mathrm{~h}$ for an initial concentration of $10 \mathrm{mg} \cdot \ell^{-1}$. This can be used to predict the performance of the bed if there is a change in the initial solute concentration. The values of $K$, $N_{0}$ and $x_{0}$ (minimum bed depth necessary to produce an effluent concentration, $C_{b}$, of $0.75 \mathrm{mg} \cdot \ell^{-1}$ ) were found to be 0.558 $\ell \cdot \mathrm{mg}^{-1} \cdot \mathrm{h}^{-1}, 428.05 \mathrm{mg} \cdot \ell^{-1}$ and $0.643 \mathrm{~cm}$, respectively.

\section{Point-of-use systems}

Point-of-use (POU) water treatment refers to a variety of different water treatment methods (physical, chemical and biological) used to improve water quality for an intended use

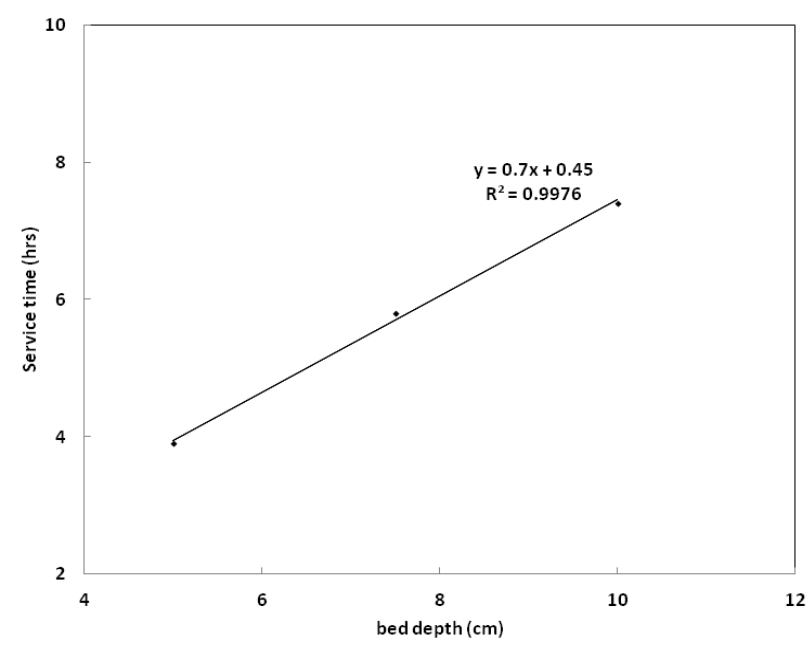

Figure 7

Effect of bed depth on service time

(drinking, bathing, washing, irrigation, etc.), at the point of consumption. POU treatment encompasses water treatment at a more decentralised scale, such as in a small community or at the household level. Furthermore, safely storing water (especially unclean water) is a huge challenge; therefore, upon water use, a POU treatment method can be applied to improve the water quality (Sobsey, 2002).

Two point-of-use systems (Figs. 2 and 3) were used to test the ability of the modified media to remove fluoride from drinking water at household level. Environmental water was sampled from 2 areas in Limpopo Province of South Africa: Venda and Lesodi, with an average fluoride concentration of 5 and $8 \mathrm{mg} \cdot \ell^{-1}$, respectively. The physic-chemical composition of the water is shown in Table 6 . The water is drunk by the local community without any treatment. Working on an average daily drinking water consumption of $20 \ell$, for a small family,

\begin{tabular}{|c|c|c|}
\hline \multicolumn{3}{|c|}{$\begin{array}{c}\text { Table } 6 \\
\text { Physico-chemical composition of the sampled field water }\end{array}$} \\
\hline Parameter & $\begin{array}{c}\text { Lesodi Motlata } \\
\text { Sample date 24/05/09 }\end{array}$ & $\begin{array}{c}\text { Venda } \\
\text { Sample date } \\
24 / 05 / 2009\end{array}$ \\
\hline $\mathrm{pH}$ & 6.81 & 6.58 \\
\hline $\mathrm{Ca}\left(\mathrm{mg} \cdot \ell^{-1}\right)$ & $>110.2$ & 112.8 \\
\hline $\operatorname{Mg}\left(\mathrm{mg} \cdot \ell^{-1}\right)$ & 10.2 & $>168.6$ \\
\hline Nitrate $\left(\mathrm{mg} \cdot \ell^{-1}\right)$ & 110 & 471 \\
\hline Fluoride $\left(\mathrm{mg} \cdot \ell^{-1}\right)$ & 8.3 & 5.3 \\
\hline $\mathrm{Na}\left(\mathrm{mg} \cdot \ell^{-1}\right)$ & $>333.5$ & $>411.2$ \\
\hline $\mathrm{K}\left(\mathrm{mg} \cdot \ell^{-1}\right)$ & 3.4 & 13.8 \\
\hline
\end{tabular}
the units were operated at a flow rate of $2 \ell \cdot h^{-1}$ for $10 \mathrm{~h} \cdot \mathrm{day}^{-1}$.

The daily performance of the units is shown in Figs. 8 to 11 . As shown in Fig. 8, Model I point-of-use unit managed to defluoridate water from Venda and Lesodi for up to a maximum of 35 and 14 days, respectively, after which the effluent fluoride concentration surpassed the maximum South African allowable limit of $0.75 \mathrm{mg} \cdot \ell^{-1}$. On the other hand, Model II POU could only be operated for 10 and 16 days for the Lesodi-sourced and Venda-sourced water, respectively (Fig. 9).

Despite the fact that Model I unit had less adsorbent as compared to Model II, its performance was better in the 2 cases studied. With Venda-sourced water, Model I performed almost twice as well as Model II in terms of treated water capacity 


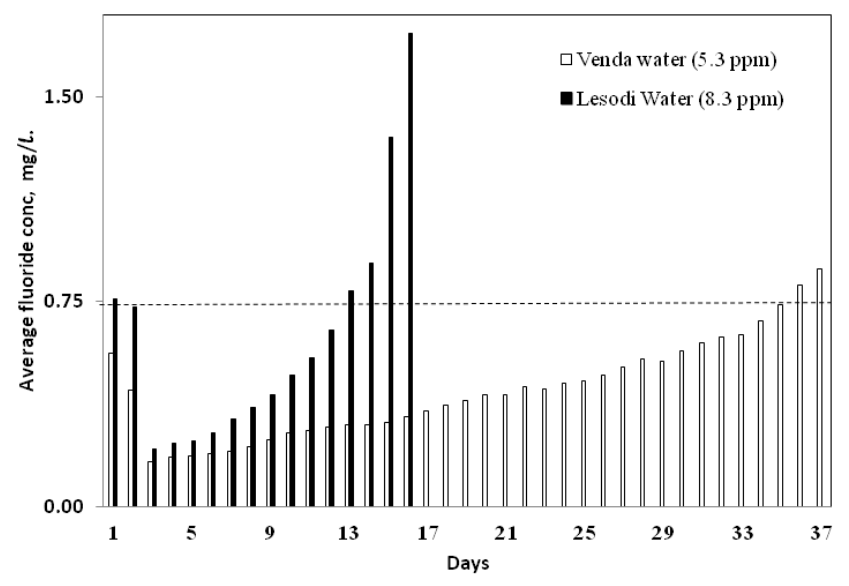

Figure 8

Model I POU system performance

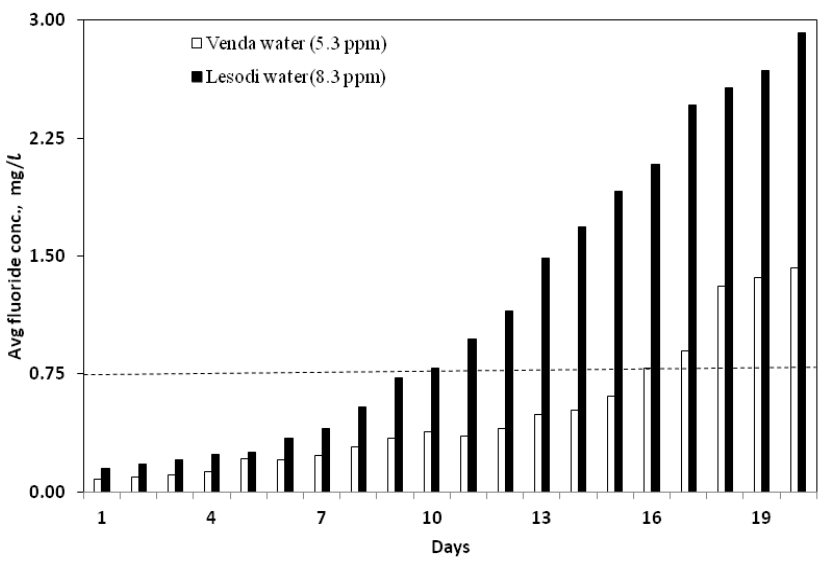

Figure 9

Model II POU system performance

(Fig. 10). The same performance variation is replicated when using Lesodi water with a different fluoride concentration, as shown in Fig. 11. It is worthwhile to note that the performance of the Model I point-of-use system stabilises after about 2 days. This is due to the air locked in the adsorbent bed which increased dispersion. Once the air is driven out, the performance of the unit normalises.

From Table 7 it is evident that the performance of POU Model I is superior to that of Model II. The performance is calculated in terms of the total volume of water treated (yield) before reaching South Africa's maximum allowable fluoride concentration of $0.75 \mathrm{mg} \cdot \ell^{-1}$, bed volume (BV) and the adsorbent fluoride uptake capacity (FUC).

\begin{tabular}{|l|l|c|c|c|}
\hline \multicolumn{5}{|c|}{ Table 7 } \\
\hline Water source & & $\begin{array}{c}\text { Yield } \\
\left(\boldsymbol{\ell} \cdot \mathbf{k g}^{-1}\right)\end{array}$ & $\mathbf{B V}$ & $\begin{array}{c}\text { FUC } \\
\left(\mathbf{m g} \cdot \mathbf{k g}^{-1}\right)\end{array}$ \\
\hline Venda & Model I & 467 & 350 & 2300 \\
& Model II & 160 & 120 & 796 \\
\hline \multirow{2}{*}{ Lesodi } & Model I & 187 & 140 & 1350 \\
\cline { 2 - 5 } & Model II & 100 & 75 & 792 \\
\hline
\end{tabular}

In Model I the flow resembles plug flow, where the lower parts of the filter bed become saturated at a time when the upper parts are still fresh. Then the saturation zone moves slowly towards the top effluent point. This kind of flow allows

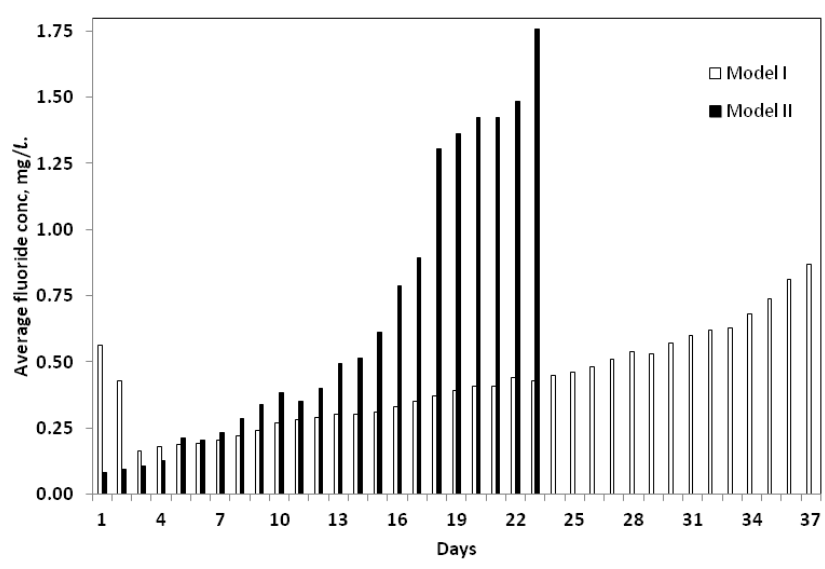

Figure 10

Comparative performance of Models I and II using Venda groundwater

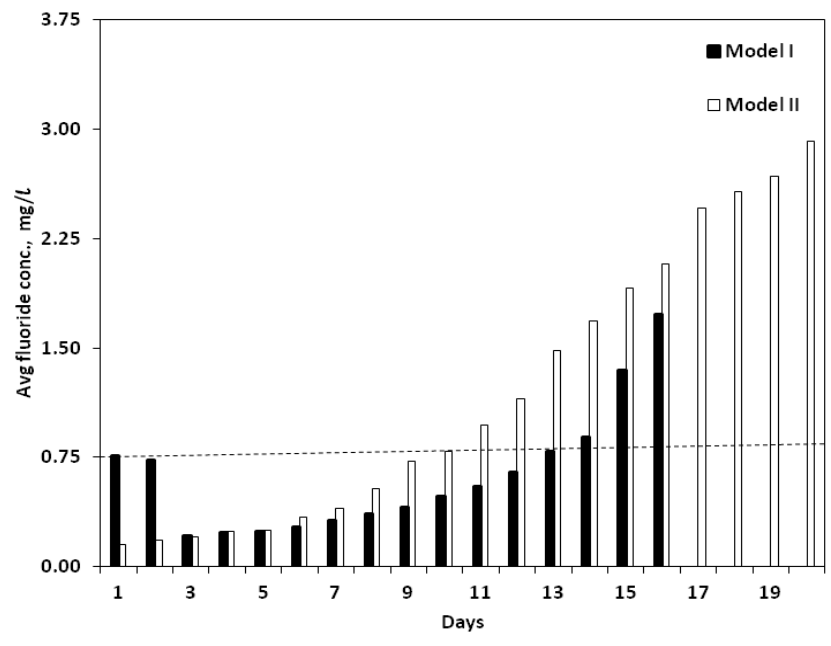

Figure 11

Comparative performance of Models I and II using Lesodi groundwater

for saturation of the medium with respect to the high fluoride raw water, hence the high capacity utilisation.

Besides this, the adsorbent runs dry after a cycle due to the gravity flow characteristic of Model II. Drying the medium results in disturbance of the sorption process and more contact time would be required to re-establish treatment, unlike Model $\mathrm{I}$, in which the adsorbent is always submerged in water during the off-periods (Fawell et al., 2006). Overall, higher fluoride uptake capacity can be due to the intermittent mode of operation of the defluoridation unit. In this mode of operation, the solid-phase fluoride concentration gradient has a chance to relax completely (approaching equilibrium) during the off-periods. This leads to a high concentration gradient between the liquid and the surface of the solid, thus resulting in improved fluoride removal when the unit is used again (Onyango et al., 2009).

\section{Conclusion and recommendations}

The thermo-chemically converted limestone exhibited effectiveness in the removal of fluoride from water. The nature of breakthrough curves was influenced by the flow rate, column bed height and initial fluoride concentration. With increased 
fluoride concentration sharp breakthrough curves were obtained. On the other hand, the breakthrough curves became gentler as the bed height increased. The thermo-chemically converted limestone adsorbent had the ability to lower the fluoride concentration of environmental water to acceptable levels, using the point-of-use systems, and can therefore be adopted as drinking water defluoridation media. Model I point-of-use unit managed to defluoridate water from Venda and Lesodi for a maximum of 35 and 14 days, respectively. Because of the longer stay of the adsorbent in the point-of-use systems, there is some possibility of microbial film growth. Further work is therefore recommended to investigate methods to mitigate this growth.

\section{References}

ABE I, IWASAKI S, TOKIMOTO T, KAWASAKI N, NAKAMURA T and TANADA S (2004) Adsorption of fluoride ions onto carbonaceous materials. J. Colloid Interface Sci. 275 35-39.

BHATNAGAR A, KUMAR E and SILLANPÄÄ M (2011) Fluoride removal from water by adsorption - A review. Chem. Eng. J. 171 811-840.

CENGELOGLU Y, KIR E and ERSOZ M (2002) Removal of fluoride from aqueous solution by using red mud. Sep. Purif. Technol. 28 81-86.

CHATURVEDI AK, YADAVA KP, PATHAK KC and SINGH VN (1990) Defluoridation of water by adsorption on fly ash. Water Air Soil Pollut. 49 51-60.

FAN X, PARKER DJ and SMITH MD (2003) Adsorption kinetics of fluoride on low cost materials. Water Res. 37 4929-4937.

FAWELL J, BAILEY K, CHILTON J, DAHI E, FEWTRELL L and MAGARA Y (2006) Fluoride in Drinking-Water. IWA Publishing, London.

GOEL J, KADIRVELU K, RAJAGOPAL C and GARG VK (2005) Removal of lead(II) by adsorption using treated granular activated carbon: Batch and column studies. J. Hazardous Mater. 125 211-220.

GONG W, QU J, LIU R and LAN H (2012) Effect of aluminum fluoride complexation on fluoride removal by coagulation. Colloid Surface A 395 88-93.

GUPTA SK (1997) A Process for defluoridation of water by a filter bed using indigenous material. Indian J. Environ. Sci. 1 (2) 149-156.

HUO Y, DING W, HUANG X, XU J and ZHAO M (2011) Fluoride removal by lanthanum alginate bead: Adsorbent characterization and adsorption mechanism Chin. J. Chem. Eng. 19 (3) 365-370.

HUTCHINS RA (1973) New method simplified design of activated carbon system. Chem. Eng. 80 133-138.

ISLAM M and PATEL RK (2007) Evaluation of removal efficiency of fluoride from aqueous solution using quick lime. J. Hazardous Mater. 143 303-310.

KETTUNEN R and KESKITALO P (2000) Combination of membrane technology and limestone filtration to control drinking water quality. Desalination 131 271-283.

LAI YD and LIU JC (1996) Fluoride removal from water with spent catalyst. Sep. Sci. Technol. 31 2791-2803.

LI YH, WANG SG, ZHANG XF, WEI JQ, XU CL, LUAN ZK and WU DH (2003) Adsorption of fluoride from water by aligned carbon nanotubes. Mater. Res. 38 469-476.

LI YH, WANG S, ZHANG X, WEI J, XU C, LUAN Z, WU D and WEI B (2003) Removal of fluoride from water by carbon nanotube supported alumina. Environ. Technol. 24 391-398.

LUTHER SM, POULSEN L, DUDAS MJ and RUTHERFORD PM (1996) Fluoride sorption and mineral stability in an Alberta soil interacting with phosphogypsum leachate. Can. J. Soil Sci. 76 83-91.

MEENAKSHI RC, GARG VK, KAVITA, RENUKA and MALIK A (2004) Groundwater quality in some villages of Haryana, India: focus on fluoride and fluorosis. J. Hazardous Mater. 106 85-97.

MEENAKSHI RC and MAHESHWARI (2006) Fluoride in drinking water and its removal. J. Hazardous Mater. 137 456-463.

MISRA AK and MISHRA A (2007) Study of quaternary aquifers in Ganga Plain, India: Focus on groundwater salinity, fluoride and fluorosis. J. Hazardous Mater. 144 438-448.

MJENGERA H and MKONGO G (2002) Appropriate defluoridation technology for use in fluorotic areas in Tanzania. 3rd WaterNet Symposium Water Demand Management for Sustainable Development, 30-31 October 2002, Dar es Salaam.

MOHAPATRA M, ANAND S, MISHRA BK, GILES DE and SINGH $\mathrm{P}$ (2009) Review of fluoride removal from drinking water. $J$. Environ. Manage. 91 67-77.

NDIAYE PI, MOULIN P, DOMINGUEZ L, MILLET JC and CHARBIT F (2005) Removal of fluoride from electronic industrial effluent by RO membrane separation. Desalination 173 25-32.

ONYANGO MS, KOJIMA Y, KUMAR A, MITSUHIRO K and MATSUDA H (2006) Uptake of fluoride by $\mathrm{Al}^{3+}$-pretreated lowsilica synthetic zeolites: Adsorption equilibria and rate studies. Separ. Sci. Technol. 41683.

ONYANGO MS, LESWIFI TY, OCHIENG A, KUCHAR D, OTIENO FO and MATSUDA H (2009) Breakthrough analysis for water defluoridation using surface-tailored zeolite in a fixed bed column. Ind. Eng. Chem. Res. 48 931-937

PIEKOS R and PASLAWASKA S (1999) Fluoride uptake characteristic of fly ash. Fluoride 32 14-19.

PINON-MIRAMONTES M, BAUTISTA-MARGULIS RG and PEREZ-HERNADEZ A (2003) Removal of arsenic and fluoride from drinking water with cake alum and a polymeric anionic flocculent. Fluoride 36 122-128.

REARDON EI and WANG YX (2000) A limestone reactor for fluoride removal from wastewater. Environ. Sci. Technol. 34 3247-3253.

REGULATIONS ON FLUORIDATING WATER SUPPLIES (2000) South Africa Government Gazette Notice 21533. Government Printers, Pretoria.

SIMATE GS, IYUKE SE, NDLOVU S, HEYDENRYCH M and WALUBITA LF (2012) Human health effects of residual carbon nanotubes and traditional water treatment chemicals in drinking water. Environ. Int. 39 38-49.

SOBSEY MD (2002) Managing Water in the Home: Accelerated Health Gains from Improved Water Supply. World Health Organization, Geneva.

TALEB R, BENGHALEM A and GHAFFOUR N (2010) Removal of excess flGHAFFO ions from Saharan brackish water by adsorption on natural materials. Desalination 250 408-413.

TURNER BD, BINNING P and STIPP SLS (2005) Fluoride removal by calcite: evidence for fluorite precipitation and surface adsorption. Environ. Sci. Technol. 39 9561-9568.

WHO (WORLD HEALTH ORGANIZATION) (2006) Guidelines for Drinking-Water Quality: Incorporating First Addendum to Third Edition. World Health Organization, Geneva. 375 pp.

XU X, LI Q, HAO C, PANG J, SUN L, HAO A and ZHAI J (2011) Adsorption of flZHAI $J$ from aqueous solution on magnesia-loaded fly ash cenospheres. Desalination 272 233-239.

YADAV AK, KAUSHIK CP, HARITASH AK, KANSAL A and RANI N (2006) Defluoridation of groundwater using brick powder as an adsorbent. J. Hazardous Mater. 128 289-293.

ZEVENBERGEN C, VAN REEUWIJK LP, FRAPPORTI G, LOUWS RJ and SCHUILING RD (1996) A simple method for defluoridation of drinking water at village level by adsorption on Ando soils in Kenya. Sci. Total Environ. 188 225-232. 
http://dx.doi.org/10.4314/wsa.v38i2.14 Available on website http://www.wrc.org.za ISSN 0378-4738 (Print) = Water SA Vol. 38 No. 2 April 2012 ISSN 1816-7950 (On-line) $=$ Water SA Vol. 38 No. 2 April 2012 